\title{
Application Exploration for Modern Teaching with Digitized Technology Introduced by Basic Physics Teaching
}

\author{
Zhicong Fang \\ School of Automotive and Electronic Engineering, Xichang College, Xichang, \\ 615013, China
}

Keywords: basic physics teaching, digitized technology, modern teaching, application exploration

\begin{abstract}
It is an objective need for introduction of digitalized technology to basic physics teaching to realize modernization of physics teaching. In this paper, a brief description is given to the importance of changing teaching thought and conception for the realization of teaching modernization. Besides, an introduction is given to the important supporting function of digitalized technology on modern teaching of basic physics. At the same time, the author lists in detailed supporting patterns of digitalized technology for modern teaching of basic physics.

China's higher education shoulders the responsibility to cultivate socialist constructers in the future. Therefore, China should stand in a leading place in the modernization of education. At present, many countries have already introduced digitalized technology into basic classroom teaching. For instance, the pattern of experimental simulation through digitalized technology has been universally applied into remote network teaching. In America, digitalized technology is greatly applied into college physics textbooks for analysis and processing of typical physical questions, thus letting students to study and research. Generally speaking, however, the digitalization degree is not enough in the field of basic physics teaching in China. Additionally, its universality and professional level are relatively slow. In the future, it is necessary for us to further enhance the exploration for modernization of basic physics teaching.
\end{abstract}

\section{Change teaching and conception first to realize modernization of teaching}

It is universally acknowledged that modernization of teaching is a key link of teaching reform. Modernization of teaching is also represented at teaching contents, teaching approaches and teaching concepts. However, the modernization of teaching concept is served as the basis and premise for the realization of modern teaching. It needs to start with the following aspects to realize the modernization of teaching thought and concept:

(I) Lay emphasis on teaching of thinking model and solution in practical teaching

Traditional basic physics teaching simply lays emphasis on teaching and learning of knowledge, while it neglects the training for students' thinking ability and the cultivation of students' innovation ability and practical application ability. Under normal conditions, teachers will not make a systematic introduction to thinking method and research method of physics for students. In basic physics teaching, teachers could hardly pay attention to application of physical thought. The viewpoint of "it is better to teach a man fishing than to give him fish" is generally accepted. For the practice of this superior educational concept, however, there is still no complete pattern or system [1]. According to the author's opinion, it is necessary to teach students basic physical knowledge in physics teaching, while physical knowledge can not be simply taught in a systematic or complete way without attention to the teaching of physical thinking models, solutions and tools or without emphasis on the training for students' initiative and practical ability to acquire knowledge. These physical thinking models, solutions, tools and abilities to acquire knowledge by themselves are just important issues in teaching. With rapidly advanced growth rate of knowledge in current information era, it is impossible for teachers to teach all basic physics knowledge on class. 
(II) Establish the teaching concept with students as principal subjects

Although China's traditional teaching pattern has many advantages, its disadvantages are also very obvious. Since the establishment of the state, China's higher education got rapid development. With the deepening of reform and opening up, China's higher education develops at an alarming rate. There are many reasons for great differences between our education and international education level. The restrictive function of traditional teaching pattern on students' innovation ability is one of significant reasons. Knowledge of Chinese students from primary school to university is taught by their teachers. Practices that students do the most are all repeated test questions [2]. Under the circumstances free from teachers' help, it is very difficult for students to acquire knowledge, analyze questions and find out solutions by themselves. Traditional teaching pattern fails to teach students relevant practices. Therefore, teachers should first change their teaching thoughts and concepts while making teaching programs. Or, modern teaching will become meaningless.

\section{Modern teaching needs to be supported by digitalized technology.}

The thought and concept of modern teaching makes us to unify our cognition, have common language and specify the reform direction. However, only ideological cognition is not enough. Modern teaching needs to be supported by advanced technology. Or, it becomes a castle in the air. It is generally acknowledged by teachers that the modernization of basic physics teaching must be realized. However, it is uneasy for the way of such realization. For instance, it is very easy just for simple introduction to physical quantum theory and nonlinear knowledge. However, it will fail to have favorable teaching effects [3] if it lacks practices associated with teaching process and there is no relevant exercise for analysis and research by students. If only analytical method is used for discussion on quantum theory and nonlinear problem, it may be not accepted by all students in lower grades and/ or not majored in this. Therefore, it is of certain difficulty to modernize basic physics teaching in practical operations.

The utilization of digitalized technology can effectively solve these issues. Practice has proved that students in lower grades can also rapidly master numerical calculation, digital simulation, digital simulation and other technologies. At the same time, these tools and technologies can be also used for quantitative research on quantum theory and nonlinear knowledge. Supporting effects of digitalized technology are mainly represented in the following aspects:

(I) Utilize digitization for setting of teaching situation

In recent years, digitalized technology is universally applied into basic physics teaching. The most prominent manifestation is to use digitalized technology to set vivid teaching situation. In basic physics teaching, students keep in remarkable contact with physical concepts and laws. Basic physical knowledge is relatively boring and abstract, difficult to be understood. Therefore, it becomes a difficulty in physics teaching. If modern digital media technologies are introduced to visually display theoretical knowledge to students through the screen while teaching of basic theoretical knowledge, it can not only properly solve students' disturbance of comprehension but also let students to deeply experience physical principles, deepen their impressions and improve students' level of knowledge mastering, so as to improve the classroom efficiency of physics teaching [4].

(II) Digitalized technology makes the knowledge direct, vivid and easy to be understood.

The application of digitalized technology can create vivid teaching situation and make physical knowledge to be displayed to students in a more direct and vivid way at the same time, so as to deepen students' impression and consolidate their mastering of knowledge. Digitalized technology can be used to present several physical situations, present many static and boring physical theories in a dynamic and direct way, become abstract physical knowledge more specific, reduce students' difficulties in comprehension, and improve the efficiency of basic physics teaching. For instance, one of teaching difficulties while teaching hydrogen atom magnon $\mathrm{m}$ is to find out the relations between $\mathrm{m}$ and quantization of angular momentum in the spatial direction [5]. Digitalized technology is used for simulation and associate directional function nodes with the component of 
angular momentum z. Good effects are achieved through analysis and research on stability of wave.

Some scholars have achieved good results in digitalized teaching of nonlinear physical knowledge, shortening teaching hours of physics courses, teaching relevant physical research thoughts, methods and tools to students, and improving students' learning ability and capability to solve problems. Through learning exploration and training, students can independently finish research papers in this field. Papers of some students even got published in some popular science periodicals [6].

(III) Digitalized technology realizes analogue simulation of physical experiment.

Physics is of very strong practice, so physical teaching can not be separated from experimental curriculum. Subject nature and restrictions of some other conditions can not be moved onto class by many physical simulation experiments. Some physical experiments may also bring about dangers. However, students will have difficulties in understanding some theoretical knowledge if there is no relevant physical experiment. However, modern teaching pattern of digitalized technology can solve this issue. Digitalized technology can be used to realize analogue simulation of physical experiment and truly represent the processes of many physical experiments. Through observations and experiences of digitalized simulation of physical experiments, students master relevant physical laws. The introduction of physical simulation experiment effectively improves students' ability to master physical knowledge, thus improving the efficiency of basic physics teaching [7].

(IV) Enrich the contents of basic physics teaching

In traditional teaching pattern, many questions designed in basic physics teaching are relatively ideal and simple, which have great differences with practical issues in scientific research and practical life and production. As a result, they may let students to feel that physical knowledge lacks practicability. However, the distance of two items is closer to a large extent by the utilization of digitalized technology. For instance, teachers can design and make the model of river crossing with a small boat while teaching mechanical motion knowledge, letting students to observe and analyze the influence of the distance from riverbank on river water speed. While tracing the problem model, teachers can randomly set tracks of the escape target. At the same time, tracing programs are also diversified. In the teaching process of dynamics, teachers can guide students to analyze spring connector, coupled pendulum, coupled oscillator and other complicated units and systems. In the teaching process of magnetism, teachers can utilize digitalized technology to display the charge distribution field and ring current magnetic field between several arbitrary points and other questions to students. In the teaching process of thermodynamics and statistic physics, teachers can use digitalized technology to simulate the speed distribution. In the nonlinear teaching process, teachers can utilize digitalized technology to simulate Duffing model, impulse rotor structure and other questions [8].

(V) Create the atmosphere of quality-oriented education and innovative education

Digitalized technology can be used to enrich the contents of basic physics teaching, make innovations to the pattern of physics teaching, and create a favorable atmosphere for quality-oriented education and innovative education at the same time. For instance, teachers can teach students solutions of practical problems, guide students for autonomous exploring learning, and import the pattern of analysis - digitalized teaching. The introduction of these teaching patterns can improve the quality of students, train their ability to solve problems, and cultivate their ability to innovate.

Practice has proved that the analysis - digitalized physics teaching pattern has remarkable effects. The settlement of a physical question is finished by only obtaining the result of analytic formula in traditional physics teaching. In many causes, however, not all students are familiar with physical thoughts and detailed contents covered in the analysis result. In particular, sometimes even teachers fail to completely figure out some complicated analytic formulas [9]. In the teaching process of quantum mechanics, for instance, the issue of wave function is involved. As prescribed in books, wave function must be a plural. Students can only understand plural wave functions and free particles involved in the analysis process. For the image of one-dimensional linear harmonic oscillator plural wave function, however, it is never mentioned in any book. Through the application 
of digitalized technology, students effectively understand and master the image of plural wave function. Moreover, they can independently solve these plural waves through learning. Through the analysis - digitalized teaching pattern, students can understand in details the analysis process and directly and vividly see diagrams, images or video clips at the same time, remarkably increasing the interestingness of class, motivating students' learning initiative, and helping students to understand and master physical knowledge in a better way. In physical textbooks, the formula for solution of long straight current carrying conductor magnetic field is given for electromagnetism. However, students will be confused when there is no continuous current in the straight conductor with a limited length. Through digitalized technology, teachers can guide students to make a research on current-carrying square coils and analyze the magnetic field distribution. Such coils are directly displayed and presented through the digitalized teaching pattern. It is easier for students to understand the application of long straight conductor magnetic field solution formula [10]. The introduction of various new teaching patterns through digitalized technology can improve students' scientific quality and innovation ability to a large extent, train students to use thinking models of physics, and cultivate students' ability to solve physical questions independently. For instance, basic physics teaching involves communication, quantum, nonlinearity, economy and other issues. However, such issues can not be solved in traditional teaching pattern. The introduction of digitalized technology allow students to master physical knowledge, thinking models and solutions in a better way, to see close relations between physics and practical life and production, and to understand practicability and importance of physics.

\section{Conclusion:}

Although the author only gives an introduction in above paragraphs to the exploration and practice process of modern basic physics education based on digitalized technology, it already fully reflects great promotion effect and deep influence of digitalized technology on basic physics teaching. The author hopes that more colleges and universities could devote into the reform research on basic physics teaching in the future, so as to further enhance the application of digitalized technology in physics teaching, and improve the modernization level of China's basic physics teaching pattern.

Acknowledgments

This paper is a scientific research project of Education Department of Sichuan Province in 2013: Design Specifications and Data Integration of Information Management System in Digitalized Campus Construction Process, Project No.: 13ZA0153.

\section{References:}

[1] Li Yuanjie and Sun Weina, Comprehensive Introduction of Digitalized Technology and Promotion of Modern Basic Physics Teaching [J], College Physics, 2003, 05 (10): 35-38;

[2] Lu Lingling, Analysis on Digitalized Technology of Basic Physics Teaching [J], Wireless Internet Technology, 2012, 08 (23): 226;

[3] Yuan Duqi, Exploration for and Innovation to Modern Basic Physics Teaching [J], Journal of Baoji University of Arts and Sciences (Natural Science Edition), 2001, 04 (15): 78-82;

[4] Liu Xiangju, Reflection on Modern Basic Physics Teaching [J], Education of Television University of China, 2000, 06 (11): 46-48;

[5] Zhou Xiaoming, Modern Science \& Technology and Modernization of Basic Physics Teaching [J], Journal of Hengyang Normal University (Natural Science), 2002, 06 (13): 67-71; 
[6] Li Guangzhou and Zhou Xiaoming, Modern Science \& Technology and Modernization of Basic Physics Teaching [J], College Physics, 2003, 05 (19): 36;

[7] He Yujiang, Sun Yabing and Luo Le, Discussion on Modernization of Basic Physics Teaching [J], Journal of Hefei University of Technology (Social Sciences), 2001, 02 (19): 163-165;

[8] Yi Lisha, Xiao Yuying and Li Suqin, Modern Teaching Methods and Basic Physics Teaching [J], Research in Higher Education of Engineering, 2000, 01 (03): 75-78;

[9] Xu Chengbing, Emphasis on Digitalized Technology in Physics Teaching [J], Math, Physics and Chemistry for Middle School Students (Teaching and Learning), 2014, 03 (21): 23;

[10] Wu Xianchao, Practice and Research of Digitized Physical Course Teaching in High School [J], Guidance on Learning of New Courses, 2013, 08 (16): 7-9. 